\title{
Atenção psicológica clínica: encontros terapêuticos com crianças em uma creche ${ }^{1}$
}

\author{
Ana Paula de Sá Campos \\ Vera Engler Cury² \\ Pontifícia Universidade Católica de Campinas, Campinas-SP, Brasil
}

\begin{abstract}
Resumo: Esta pesquisa objetivou analisar a potencialidade terapêutica de encontros realizados pela pesquisadora com crianças de três a seis anos no contexto de uma creche. O referencial teórico utilizado foi a Abordagem Centrada na Pessoa, fundamentado na proposta terapêutica de Virgínia Mae Axline, denominada Ludoterapia Centrada na Criança. As próprias crianças geraram a estrutura dos encontros, estabelecendo com a pesquisadora uma relação que guarda semelhanças com o plantão psicológico. Trata-se de um estudo fenomenológico que adotou a construção de narrativas baseadas nos encontros terapêuticos realizados na instituição. As narrativas possibilitaram uma análise fenomenológica da relação intersubjetiva vivida nos encontros. Os resultados demonstraram a capacidade das crianças em: assumir a iniciativa pela procura espontânea por uma relação de ajuda psicológica; comunicar sentimentos a respeito de si mesmas e de seus problemas; compreender e colaborar para a estruturação da relação de ajuda psicológica.
\end{abstract}

Palavras-chave: aconselhamento, ludoterapia, fenomenologia, pesquisa qualitativa.

\section{Psychological clinical care: therapeutic encounters with children in a daycare center}

\begin{abstract}
This study aimed to analyze the therapeutic potential of encounters held by the researcher with children three to six years of age within the context of a daycare. Person-Centered Approach was the theoretical reference used. It is based on the therapeutic proposal of Virginia Mae Axline, known as Child Centered Ludotherapy. Children themselves set up the encounters' structure and established with the researcher a relationship similar to the clinical intervention known as On Duty Psychology. This phenomenological study adopted the construction of narratives based on therapeutic encounters held at the institution. The narratives permitted a phenomenological analysis of the intersubjective relationship experienced during encounters. Results revealed children's ability to: took the initiative to spontaneously seek for psychological help; communicate feelings regarding themselves and their problems; understand and collaborate to the construction of the psychological help relationship.
\end{abstract}

Keywords: counseling, play therapy, phenomenology, qualitative research.

\section{Atención psicológica clínica: encuentro terapéutico infantil en guardería}

\begin{abstract}
Resumen: Este estudio tiene como objetivo analizar el potencial terapéutico de las vivencias realizadas por la investigadora con niños de tres a seis años considerando el nido como ambiente de trabajo. La referencia teórica utilizada fue el Enfoque Centrado en la Persona, fundamentándose una respuesta terapéutica de Virginia Mae Axline, denominada Ludoterapia Enfocada en el Niño. Los mismos niños crearán la estructura de los encuentros, estableciendo con la investigadora una relación de semejanza con el plano psicológico. Se trata de un estudio fenomenológico que adaptó la construcción de relatos en base a los encuentros terapéuticos realizados en la institución. Los relatos permitirán el análisis fenomenológico de la relación ínter subjetiva de los encuentros. Los resultados demostraron que los niños que participaron: pueden asumir la iniciativa de una búsqueda espontánea por una relación de ayuda psicológica; fueron capaces de comunicar sentimientos genuinos de ellos mismos y de sus problemas durante los encuentros terapéuticos; fueron capaces de comprender y colaborar para estructurar la relación de ayuda psicológica.
\end{abstract}

Palabras clave: aconsejar, ludoterapia, fenomenología, investigación cualitativa.

O presente artigo deriva de uma dissertação de mestrado que consistiu em um estudo fenomenológico que objetivou analisar encontros terapêuticos realizados pela pesquisadora com crianças de três a seis anos em uma creche, sob a perspectiva teórica da Psicologia Humanista. Pretendeu-se analisar a potencialidade mutativa do encontro terapêutico como um enquadre clínico diferenciado, apropriado ao exercício de uma prática psicológica clínica em instituição, com

1 Apoio: CNPq. Este artigo é derivado da dissertação de mestrado defendida pela primeira autora, sob orientação da segunda, no Programa de Pós-graduação em Psicologia da Pontifícia Universidade Católica de Campinas. Este texto foi revisado seguindo Acordo Ortográfico da Língua Portuguesa (1990), em vigor a partir de $1^{\circ}$ de janeiro de 2009.

2 Endereço para correspondência:

Profa. Dra. Vera Engler Cury. Pontifícia Universidade Católica de Campinas. Programa de Pós-graduação em Psicologia. Centro de Ciências da Vida. Av. John Boyd Dunlop, s/n. CEP 13060-904. Campinas-SP, Brasil.E-mail:vengler@puc-campinas.edu.br ênfase na criação de um espaço de escuta e acolhimento disponibilizado às crianças no cotidiano da creche.

$\mathrm{O}$ interesse pelo tema desta pesquisa originou-se durante a graduação, quando a pesquisadora esteve em contato com a mesma creche, onde realizou este estudo. Chamou-lhe a atenção a aprendizagem que teve ao acompanhar e estar inserida em um cotidiano tão adverso de uma comunidade em que as relações eram pautadas por extrema violência, onde, ao mesmo tempo, presenciavam-se exemplos de criatividade, espontaneidade e autonomia por parte de crianças desse mesmo contexto. Questionou-se, então, sobre como era possível a estas crianças preservar a saúde e o potencial para o crescimento, o que constituiu um dos motivos pelo qual buscou o mestrado, a saber, o interesse em pesquisar e interagir com tais crianças sobre o que Rogers (1980) denominou de "tendência atualizante". Ao longo da pesquisa, juntamente com a orientadora, a pesquisadora foi delineando o foco e o 
tema, respeitando as necessidades trazidas pelas crianças a partir da configuração dos encontros terapêuticos.

Dessa forma, a fundamentação teórica da pesquisa pautou-se na Psicologia Humanista e, de modo mais específico, na Abordagem Centrada na Pessoa (ACP), criada pelo psicólogo norte-americano Carl Ransom Rogers (1902-1987). Por se tratar de crianças, buscou-se também contribuições da Ludoterapia Centrada na Criança, desenvolvida por Virgínia Mae Axline, discípula de Rogers.

$\mathrm{O}$ criador da ACP definiu determinadas condições facilitadoras que, quando estabelecidas em uma relação de ajuda, potencializam o desenvolvimento psicológico do cliente. Rogers e Kinget (1977, p. 39) afirmam que essa abordagem parte do seguinte princípio:

Todo ser humano tem a capacidade de compreender-se a si mesmo e de resolver seus problemas de modo suficiente para alcançar a satisfação e eficácia necessárias ao funcionamento adequado. (...) Ele tem igualmente uma tendência para exercer esta capacidade. (...) Esta capacidade é entendida como integrante de seu conteúdo natural, (...) mas a atualização eficaz desta potencialidade não é automática.

Rogers (1980) afirma que essa potencialidade só ocorre em uma relação intersubjetiva, quando existe um ambiente facilitador para tal expressão e o cliente sente-se aceito e acolhido pelo terapeuta. É esta potencialidade que Rogers denomina "tendência autoatualizante", um dos conceitos centrais de sua teoria, que propõe ser essa uma tendência organísmica, já que para este autor as qualidades fundamentais da natureza humana são crescimento, processo e mudança (Freire, 2000). Um bom exemplo que Rogers oferece sobre a tendência atualizante diz respeito ao momento em que o bebê que engatinha começa a realizar tentativas para locomoverse sobre os dois pés, muitas vezes ele cai e machuca-se, mas isso não o impede de prosseguir. $\mathrm{O}$ organismo tende a satisfazer suas próprias necessidades a despeito das adversidades e o indivíduo comporta-se como um todo organizado na sua interação com a realidade.

A Ludoterapia Centrada na Criança surgiu como uma aplicação da ACP; foi inicialmente desenvolvida por Rogers e posteriormente aprimorada por Virgínia Mae Axline, sua discípula na Universidade de Chicago e companheira de trabalho no Centro de Aconselhamento. A obra mais importante de Axline foi publicada em 1947, com o título Ludoterapia: A dinâmica interior da infância (Axline, 1947/1984), esse livro tornou-se um clássico e foi prefaciado pelo próprio Rogers. Mais tarde, Axline publicou um segundo livro na forma de romance, que relata o processo psicoterapêutico de uma criança, cujo título é Dibs em busca de si mesmo (Axline, 1974).

Os princípios básicos da Ludoterapia Centrada na Criança preconizados por Axline (1947/1984) são: estabelecimento de rapport; aceitação da criança como ela é; permissividade no relacionamento do terapeuta com o cliente; identificação e reflexo de sentimentos como atitudes terapêuticas; profundo respeito pela capacidade da criança; permitir que a criança indique o caminho; considerar que o processo terapêutico é gradativo e estabelecer os limites de realidade para nortear a relação com a criança.

A pesquisadora do presente artigo inspirou-se na proposta de Rogers e Axline sobre a Ludoterapia Centrada na Criança ao desenvolver os encontros terapêuticos com as crianças no contexto da creche. Adotou as atitudes facilitadoras de aceitação positiva incondicional, empatia e autenticidade, permitiu que cada criança pudesse beneficiar-se do espaço terapêutico à sua própria maneira.

Deve ser destacado também o conceito da "não diretividade": para Rogers o importante não é a ausência de diretivas, mas a presença autêntica do terapeuta pautada por atitudes e não por técnicas. Buys (2001, p. 5) afirma que: "a não diretividade como conceito é uma afirmação; é uma tomada de posição quanto ao ser humano que implica sua valorização e seu desenvolvimento livre e autônomo. Ela não é uma recomendação baseada no bom senso".

A não diretividade pode ser traduzida como a preservação da autonomia do cliente ao longo do processo terapêutico. Assim, a pesquisadora foi construindo os encontros terapêuticos a partir das necessidades e escolhas que as crianças foram realizando, desde quando demonstraram o desejo de contar-lhe sobre situações vividas por elas e suas percepções a respeito. Esse aspecto pode ser considerado também um diferencial na configuração da própria pesquisa, demonstrando a importância de se construir novos caminhos para delinear o trajeto de pesquisas qualitativas de base humanista em contextos naturais.

O fato de não terem sido desenvolvidas muitas pesquisas com crianças por pesquisadores da ACP, desde os trabalhos pioneiros de Axline, contribuiu para que a pesquisadora pudesse criar uma estratégia de investigação para realizar este estudo.

\section{Método}

A seguir realizam-se algumas considerações sobre o método que delineou o caminho deste estudo. Houve duas etapas importantes: o processo de inserção da pesquisadora na creche e a construção de narrativas como um modo fenomenológico de analisar as experiências vividas nos encontros terapêuticos.

\section{Aspectos éticos}

Quanto às questões éticas, para a realização desta pesquisa, tomou-se o cuidado de realizar uma palestra para os pais das crianças da creche, explicando sobre a atuação da pesquisadora: dias e períodos em que ela compareceria às atividades, sua intenção a respeito da pesquisa, a necessidade de registro de algumas falas das crianças e, por fim, o compromisso de realizar um feedback da pesquisa para os pais e 
educadores. Todos os pais autorizaram a participação de seus filhos e assinaram o Termo de Consentimento Livre e Esclarecido e, no decorrer do trabalho, alguns deles procuraram a pesquisadora a fim de tirarem algumas dúvidas. Ou seja, além do vínculo com as crianças, foi estabelecido também um bom vínculo com os pais dos participantes.

\section{A inserção da pesquisadora em campo e a configuração dos encontros terapêuticos com crianças}

É importante enfatizar que esta creche pertence a um bairro carente de recursos econômicos na cidade de Campinas, interior de São Paulo. O espaço físico do local é pequeno para as 70 crianças que lá estão inseridas, porém é estruturado, dividido em três salas por faixa etária, equipadas com brinquedos doados. Há também um espaço ao ar livre, o "parquinho" onde se desenrolou a maior parte do contato da pesquisadora com as crianças. A equipe que trabalha na creche é composta por uma assistente social, uma pedagoga, uma agente administrativa, uma faxineira, uma cozinheira, duas professoras de educação infantil cedidas pela Prefeitura (por uma espécie de convênio) e três monitoras que auxiliam nas atividades de recreação das crianças.

Os encontros com as crianças foram sendo configurados a partir de um período de observação da pesquisadora. Inicialmente, sua participação concentrou-se em acompanhar as atividades rotineiras da creche, visando compreender como se davam as relações interpessoais entre os funcionários da instituição e destes com as crianças. Este período também facilitou a interação e o estabelecimento de vínculo da pesquisadora com as crianças.

O primeiro contato com os participantes constituiu-se por um acolhimento imediato e carinhoso que se sucedeu à apresentação feita pela pedagoga da creche, que desempenhou papel importante na configuração do tipo de vínculo que a pesquisadora viria a estabelecer com as crianças. A pedagoga solicitou às crianças para que se sentassem em círculo e apresentou a pesquisadora da seguinte forma:

Crianças, prestem atenção, esta é a "tia P.", ela vai estar aqui com a gente todas as quintas e sextas de manhã para conhecer vocês, conversar com vocês; vocês podem chamá-la para algumas brincadeiras, mas o que mais a "tia P." vai querer saber de vocês é se vocês têm algum probleminha em casa, se estão chateados com alguma coisa... sabe assim, quando, por exemplo, o papai e a mamãe de vocês brigam por algum motivo e deixam vocês chateados? Vocês podem procurar a "tia $P$.” para conversar!

A estrutura dos encontros foi sendo formada nas semanas subsequentes, tomando-se por base as atitudes espontâneas das próprias crianças no relacionamento com a "tia P". Essa configuração foi construída pela forma como as crianças vinham conversar com a pesquisadora: individualmente contavam suas experiências em casa com os familiares, concentrando-se nas dificuldades vividas. Essas conversas particulares eram acompanhadas por brincadeiras, tais como: brincar de casinha, de super-herói, e principalmente, fazendo comidinhas com a areia do parquinho.

Outra questão que se destacou no desenrolar da pesquisa foi a maneira como o local dos encontros também foi definido pelas próprias crianças: elas não escolheram uma sala, embora até houvesse salas disponíveis na instituição; preferiram ir até a brinquedoteca ou ao refeitório da creche, quando estavam desocupados. Inicialmente, o que acontecia era: a criança estava no parquinho e pedia à "tia P." para conversar com ela. A psicóloga saía com a criança do parquinho, após avisar a professora responsável, e a levava até a algum destes espaços. Dessa forma, a criança passeava um pouco pela creche e ficava claro que queria mais a atenção individual ou o afeto da "tia P." do que propriamente contarlhe algo sobre si mesma. Foi então que uma das crianças resolveu conversar com a "tia P." no próprio parquinho, convidando-a para sentar no tronco de uma frondosa árvore. Estava estabelecido, assim, o que viria a ser o setting terapêutico dos consecutivos encontros que a pesquisadora fez na creche com diversas crianças.

Os encontros constituíram-se em uma modalidade de atenção psicológica clínica que guarda semelhança com o plantão psicológico, uma vez que a estrutura dos encontros condiz com a proposta do plantão. Segundo Tassinari (2003), a ideia de Plantão como um serviço, como é conhecido atualmente, foi usada pela primeira vez em 1790, quando o soldado de serviço de um oficial superior levava as ordens:

Era assim denominado porque ele ficava plantado (de pé) em um lugar. No sentido figurado, significava a situação de uma pessoa que espera de pé. Portanto, estar plantado é estar fixado na terra, aguardando, é estar disponível. É o sentido figurado de planta como algo vivo que se desenvolve, que cresce e precisa ser bem plantada aproxima-se da ideia de um Plantão Psicológico. (p. 13)

O cenário dos encontros entre a pesquisadora e as crianças foi então a sombra de uma frondosa árvore, como já citado anteriormente. Portanto, a própria imagem deste ambiente alude a uma linguagem poética, importante para a caracterização dos encontros, que faz lembrar a bela metáfora que Morato (1999, p. 13) oferece durante uma entrevista em que define o Plantão Psicológico: "Um local onde existe uma sombra para o caminhante do 'deserto da vida', para que ele possa se recuperar, encontrar abrigo e continuar sua viagem".

No caso dos encontros com as crianças, havia de fato a árvore e sua sombra que abrigou as instigantes conversas. Foi nesse contexto que se deu essa modalidade de plantão psicológico: a pesquisadora passou a posicionar-se semanalmente no lugar determinado pelas próprias crianças, sob a sombra de uma árvore, esperando por aquelas que quisessem 
(ou sentissem necessidade) vir contar-lhe algo. A pesquisadora disponibilizou-se a estar com as crianças, ouvindo-as com atenção, com uma atitude de empatia e aceitação positiva incondicional, preocupando-se em corresponder àquelas iniciativas tão espontâneas, congruentes com cada uma das crianças em sua maneira peculiar de ser e de fazer contato.

\section{A narrativa como um modo de analisar experiências em um estudo fenomenológico}

A pesquisa desenvolveu-se como uma interpretação do acontecer clínico que emergiu de encontros terapêuticos entre a pesquisadora e as crianças no contexto de uma creche. Esse foi o modo fenomenológico de apreender o significado da experiência, atribuindo-lhe significado. O fenômeno estudado emergiu e foi compreendido no contexto natural das relações que constituíram um enquadre clínico diferenciado.

Após a análise de todas as narrativas construídas pela pesquisadora, foram escolhidas cinco, tendo como critérios a relevância de seu conteúdo e a representatividade em relação ao coletivo da creche. Cada encontro terapêutico durava em média 40 minutos, a pesquisadora procurava respeitar o ritmo de cada criança em aprofundar-se nos conteúdos conflituosos.

Amatuzzi (2003) afirma que, se o pesquisador pretende fazer uma análise fenomenológica, o melhor relato é o que procura trazer - tornar presente - a experiência vivida. Nesse caso, esta pesquisa tornou-se um excelente campo para o exercício de um modo fenomenológico de pesquisar, pois a intervenção constituiu-se como tal a partir da interação da pesquisadora com as crianças, tendo como objeto de estudo aquilo que foi vivenciado intersubjetivamente durante os encontros. A descrição, a compreensão e a interpretação do vivido pela via da construção de narrativas possibilitaram presentificar as diversas camadas da experiência vivida. Em contrapartida, como a experiência humana é sempre polissêmica, a leitura das narrativas possibilita a atribuição de novos significados e assim o fenômeno se desdobra e pode ser apreendido sempre de maneira atualizada.

Walter Benjamin (1936/1994), crítico literário e filósofo alemão, enfatizou o papel da narrativa oral como uma forma de preservação da experiência individual e coletiva das comunidades que lhe parecia ter sido negligenciada pelas sociedades ocidentais após o advento do processo de industrialização. Segundo ele, "metade da arte de narrar está em evitar explicações” (p. 203).

O uso de narrativas como método de pesquisa é relevante pois possibilita à pesquisadora ser afetada pelas histórias dos participantes e ainda permite mediar a relação estabelecida entre pesquisador e pesquisado (Aiello-Vaisberg, Machado, \& Ambrosio, 2003). Isso faz com que o objeto da pesquisa constitua-se em reflexões referentes à própria experiência, revelando o objeto da análise como uma modalidade de mediação dialógica. $\mathrm{O}$ pesquisador assume sua própria subjetividade como parte do processo vivido com os participantes da pesquisa na construção de práticas psicológicas clínicas em instituições.

\section{Resultados e Discussão}

Neste estudo, foram elaboradas cinco narrativas com base nos encontros terapêuticos realizados. Elas traduzem o caráter intersubjetivo da experiência, protagonizada por cinco crianças que buscaram a "tia P." para conversar sobre seus problemas em encontros semanais que aconteceram no parquinho. A seguir serão transcritos pequenos trechos de algumas narrativas a fim de ilustrar a intensidade da experiência vivida:

(1) Trecho da narrativa intitulada "Vitor, o que queria muito uma festa de aniversário":

Nos primeiros encontros com Vitor, percebia-se sua grande dificuldade para expressar sentimentos. Ele brincava isolado e procurava a pesquisadora para conversar, mantendo algum brinquedo nas mãos. Certa vez, o brinquedo era um objeto bem pontiagudo, cujas pontas ele batia no chão como uma marreta, e dizia que queria cavar um buraco no chão para entrar dentro e não sair de lá nunca mais. Ninguém o acharia. Nem a mãe, nem a polícia, se esta corresse atrás dele, nem a professora da creche o alcançaria. Mas, a pesquisadora perguntou se ela poderia ir com ele e começaram a imaginar uma cena: o que haveria neste buraco?

(2) Trecho da narrativa intitulada "A raiva de Bernardo":

A pesquisadora estava apreensiva com a notícia de que o pai de Bernardo havia falecido, já que desde o último encontro ficara pensando no forte vínculo que ele tinha com o pai e sobre a importância dele para o menino. Então, a pesquisadora foi até a sala de aula onde estava a turma dele. Logo que Bernardo a avistou, correu em sua direção e pegou sua mão: "Você sabia que meu pai morreu?”. Contou, então, tudo o que a pedagoga havia relatado: que o pai tinha morrido e que até tinha ido ao enterro do pai, mas em seguida dizia que era mentira e que a avó tinha garantido para ele que o pai só estava viajando e que na noite anterior ficaram olhando as estrelas e se perguntando quando o pai voltaria, e ainda terminou assim: "Eu sei que, desta viagem, ele agora não volta mais". Demonstrava saber que estavam tentando enganá-lo para protegê-lo, mas ele sabia muito bem qual era a verdade e tentava suportar.

(3) Trecho da narrativa intitulada "Simone, aquela que não comia":

A pesquisadora ficou pensando que, de fato, a criança estava demonstrando não ter por perto nenhum adulto importante que a protegesse e lhe servisse de 
referência. O sentimento de rejeição que Simone parecia viver sempre deixava a pesquisadora em conflito. Ouvir coisas como: "Tia, eu posso ir morar com você?", fazia-a pensar que poderia ser uma das poucas pessoas que a escutava e levava a sério suas angústias. Era como se aquela criança estivesse cobrando, aos gritos: "Cadê a minha mãe? Cadê o meu pai? Quem vai cuidar de mim? Eu preciso achar alguém que me proteja!".

Cada narrativa era acompanhada da compreensão psicológica que incluía uma análise sobre: (a) modo de interação da criança com a pesquisadora ao longo dos encontros; (b) os sentimentos comunicados pela criança sobre a relação com os pais e/ou outros adultos significativos; (c) os sentimentos da criança em relação a si mesma; (d) uma síntese da dinâmica psicológica da criança.

Considerando-se que as narrativas dos encontros terapêuticos constituíram uma forma intersubjetiva de compreensão e análise, mais do que uma descrição dos fatos ocorridos, é possível que um psicólogo familiarizado com técnicas de avaliação considere as narrativas demasiadamente pueris, e até certo ponto elas o são; contudo, não tanto pela mesmice dos temas abordados, mas sim pela intenção da pesquisadora de apreender os significados da experiência vivida, ao longo das inúmeras conversas com essas e outras crianças da creche. Esses encontros estenderam-se por um período de um ano e meio, duas vezes por semana. A tristeza surgiu muitas vezes como a experiência mais autêntica da pesquisadora face aos sentimentos de solidão e abandono expressados pelas crianças. Todavia, esse sentimento foi abrandado, e até mesmo superado, à medida que aumentava sua crença na capacidade daquelas crianças para enfrentarem com coragem e com uma boa dose de inventividade os problemas vividos. Em contrapartida, a possibilidade de compartilhar as experiências das crianças constituiu-se em um privilégio. Ao perceber que seus sentimentos eram compreendidos e aceitos, as crianças pareciam desabrochar mais confiantes em si mesmas e no mundo; sentimentos de vergonha, ao serem aceitos e compreendidos como algo que pode ser respeitado, passaram a ser menos importantes e foram simbolizados como naturais.

A relação estabelecida entre as crianças e a pesquisadora foi de respeito mútuo, o que facilitou para ambas a intimidade dos encontros. Gradualmente, foi sendo estabelecido o vínculo com cada criança, respeitando-se o tempo e o limite de cada uma, deixando que elas trouxessem, além dos fatos - até porque estes eram conflitantes, e levava um tempo para que pudessem entrar em contato com eles - a própria experiência. Axline (1947/1984) e Rogers (1980) enfatizaram a importância de que o terapeuta não apresse o ritmo dos clientes em desnudar-se ao longo do processo terapêutico.

Como pôde ser apreciado nos trechos das narrativas aqui expostas, os sentimentos mais frequentes apresentados pelas crianças nos encontros foram de abandono e rejeição por parte de adultos significativos. Revelou-se um tipo de configuração familiar que resulta em modalidades de rearranjos sociais, nem sempre favoráveis ao desenvolvimento psicológico dos filhos. Na dinâmica das famílias envolvidas é frequente encontrar muitas pessoas que coabitam o mesmo espaço físico: tios que vêm de longe, primos, avós, parentes distantes que vão e voltam, vinculam-se e de repente partem. A própria figura paterna é algo bem instável nessa comunidade. Muitas crianças contam não saber do pai e possuem curiosidade extrema por essa questão, outras vezes os pais são presos por longos períodos e perdem o vínculo com as crianças. Por sua vez, as mães arranjam outros companheiros com receio de ficarem desprotegidas e os filhos dessas diversas uniões vão aprendendo a conviver.

Todas as crianças que participaram desta pesquisa contribuíram para ilustrar o conceito rogeriano de uma tendência atualizante presente nos seres humanos e responsável por conduzi-los na direção do crescimento e de uma valorização de si mesmos e das pessoas que estão à sua volta, imprimindo uma tendência à saúde e à vida coletiva. Esta potencialidade pode desenvolver-se melhor quando o indivíduo dispõe de um ambiente no qual estão presentes relações interpessoais significativas que the oferecem condições facilitadoras para um crescimento saudável (Rogers \& Kinget, 1977; Rogers, 1980).

Este estudo também possibilitou uma análise acerca das condições que podem favorecer o processo de autonomia das crianças, ao trazer à tona elementos vividos por elas, ou seja, como elas percebem, sentem e comunicam suas necessidades mais imediatas. Cabe aos pais e educadores encontrar maneiras de atender a estas necessidades, contribuindo para que o processo de desenvolvimento psicológico seja potencializado, a despeito de circunstâncias sociais adversas. Este olhar a partir da perspectiva da própria criança contrasta com uma análise objetiva e exteriorizada que muitas vezes é adotada pelos órgãos responsáveis pela elaboração de políticas públicas.

Os encontros com as crianças permitiram apreender que em uma instituição, como a creche em questão, as crianças poderiam beneficiar-se de uma escuta atenta e de um acolhimento emocional mais competente por parte da equipe.

As crianças que participaram deste estudo estão inseridas em contextos em que prevalecem relações humanas pautadas pela violência, impedindo-as de um envolvimento mais lúdico com as pessoas e o mundo; convivem diariamente com situações que as expõem a riscos, além de sofrerem agressões por parte dos adultos que deveriam protegê-las. A própria creche foi assaltada quatro vezes durante o período em que a pesquisa foi realizada, em uma delas, por um adolescente que quando criança foi atendido pela instituição. No entanto, a alimentação dessas crianças é basicamente suprida por cinco refeições diárias disponibilizadas pela creche. Resumindo, essas crianças, assim como milhares de outras, sofrem enormes constrangimentos ao longo de seu desenvolvimento. No entanto, o que se pode fazer na prática?

As narrativas são ilustrativas a esse respeito. As crianças espantavam-se com a possibilidade de escolher onde 
conversar com a pesquisadora, pois não estavam habituadas a terem suas ideias e sentimentos valorizados, pois os adultos geralmente agiam de maneira autoritária e invasiva, bem diferente da proposta de Rogers (1980) sobre a necessidade de atitudes de compreensão empática e aceitação incondicional. Percebia-se que a equipe até tentava ir ao encontro das necessidades das crianças, porém na prática não havia espaço para aquelas crianças com as "asinhas de fora", e as mais criativas, geralmente, eram as mais tolhidas, com frases do tipo: "O que você pensa que está fazendo? Olha as regras, menino! Por que você está brincando de maneira diferente?".

As narrativas elaboradas, tomando-se por base a relação entre a pesquisadora e as crianças protagonistas, constituíram-se em uma das etapas mais criativas no processo de elaboração desta investigação. Tais histórias foram inspiradas na riqueza do mundo infantil, pleno de significados e de sentimentos comunicados de forma direta, com espontaneidade, em relação aos adultos significativos, aos colegas da creche e a si mesmas. Os encontros foram coloridos por histórias cheias de vida e coragem, divididas com a pesquisadora com uma confiança comovedora. Esses resultados deram à pesquisadora a confirmação de que havia escolhido um método apropriado para realizar pesquisas com crianças: ir a campo, conquistar o vínculo e perceber, gradualmente, as necessidades dos participantes. Uma das necessidades mais recorrentes foi a de ter mais próximo alguém que lhes fosse muito querido, a mãe, o pai, ou os irmãos, ou seja, a pesquisadora pôde sentir a solidão vivida por aquelas crianças, de maneira intensa e avassaladora. Crianças são seres humanos dignos de valorização e com potencial para o crescimento (Axline, 1947/1984).

A pesquisadora conclui que os encontros terapêuticos realizados com as crianças proporcionaram a elas um espaço de crescimento, de retomada da autonomia pessoal e da autoconfiança. Quando uma situação de conflito, de dificuldade, é dividida com outra pessoa genuinamente interessada, desencadeia-se na pessoa atendida um processo de autovalorização que traz em seu bojo o potencial para a resolução dos problemas.

Uma das principais dificuldades vividas pela pesquisadora foi aceitar as faltas frequentes das crianças à creche. Uma criança em especial que estava mergulhada em um processo intenso de autodescoberta e que trazia a cada novo encontro seus sentimentos de maneira muito vívida, repentinamente, deixou de vir à creche a partir de uma mera comunicação por parte de um dos pais, sem que fosse esclarecido o motivo. A pesquisadora admite que esses são imprevistos que podem surgir ao longo de um estudo, porém vivenciou um sentimento de frustração pela falta de continuidade de um processo que parecia estar sendo importante para a criança.

Szymansky (2006) desenvolveu uma pesquisa que revelou determinadas práticas adotadas pelas famílias como forma de socialização de seus membros mais jovens, destacando que essas fundamentam a constituição identitária no que diz respeito ao processo relacional. Essas trocas intersubjetivas, situadas social e historicamente, com uma orientação valorativa e afetiva, referem-se à experiência individual ou coletiva de ser si-mesmo. Esse foi um aspecto que se tornou bastante evidente neste estudo, pois nos encontros terapêuticos as crianças adquiriram nome e espaço para a expressão dos sentimentos individuais.

Finalmente, a atenção psicológica, aqui desenvolvida e problematizada, não se furta à sua dimensão ética, uma vez que o propósito da atenção psicológica não se dirige à mudança no padrão de comportamento, mas sim à retomada da autonomia pessoal como medida profilática para potencializar um desenvolvimento saudável. Alguns elementos significativos que emergiram dos encontros terapêuticos com as crianças da creche podem ser assim resumidos: (a) capacidade de iniciativa por parte das crianças e a procura espontânea por uma relação de ajuda psicológica; (b) capacidade de compartilhar a estruturação da relação de ajuda e de assumir responsabilidade por sua manutenção; (c) demanda pela presença de um adulto que escute, compreenda e possa compartilhar o despertar de novos significados; (d) compreensão a respeito da dimensão temporal da relação vivida de maneira intersubjetiva pela criança, a pesquisadora decidia com a criança a duração dos encontros, tanto para iniciá-los quanto para encerrá-los; (e) atitude de empatia que as crianças foram estabelecendo em relação à necessidade de determinado colega ser atendido primeiro, num determinado dia, por estar mais aflito que elas para conversar com a "tia P.", inclusive sugerindo à pesquisadora para que assim o fizesse; (f) compreensão e respeito pela privacidade dos encontros; falavam: "Não vai lá agora, a 'tia P.' está conversando com a Débora"; (g) finalmente, capacidade da pesquisadora de corresponder à demanda comunicada pelas crianças por meio de atitudes de aceitação positiva incondicional, compreensão empática e autenticidade.

\section{Considerações finais}

Os encontros com as crianças confirmaram o potencial de crescimento da tendência atualizante inerente ao ser humano, e também trouxeram à tona a necessidade comunicada por elas de poderem contar com a presença de adultos capazes de facilitar a emergência de significados acerca das próprias experiências, ao longo do processo de desenvolvimento.

Por ser esta pesquisa inspirada na Abordagem Centrada na Pessoa, há também uma contribuição no sentido de corroborar a forma como essa abordagem compreende o desenvolvimento psicológico da criança: em um ambiente provido com atitudes facilitadoras por parte de adultos significativos, a criança sente-se segura e encorajada a expressar seus sentimentos mais íntimos e conflituosos, permitindo-se elaborar seus próprios significados, construindo um self saudável, apesar das dificuldades vividas

Deve-se enfatizar que esta pesquisa possibilitou uma releitura dos principais expoentes da Abordagem Centrada na 
Pessoa e permitiu um posicionamento atual da pesquisadora acerca da atenção psicológica à criança em contextos institucionais, retomando o caminho trilhado por Virgínia Axline na década de quarenta do século vinte. Espera-se que novas pesquisas possam inspirar-se neste trabalho e assim dar continuidade ao desenvolvimento da Psicologia Humanista.

\section{Referências}

Aiello-Vaisberg, T. M. J., Machado, M. C. L, \& Ambrosio, F. F. (2003). A alma, o olho e a mão: Estratégias metodológicas de pesquisa na psicologia clínica social winnicottiana. In T. M. J. Aiello-Vaisberg \& F. F. Ambrosio (Orgs.), Cadernos ser e fazer: Vol. 1. Trajetos do sofrimento humano: Desenraizamento e exclusão (pp. 6-16). São Paulo: Instituto de Psicologia da Universidade de São Paulo.

Amatuzzi, M. M. (2003). Pesquisa fenomenológica em psicologia. In M. A. T. Bruns \& A. F. Holanda (Orgs.), Psicologia e fenomenologia: Reflexões e perspectivas. São Paulo: Alínea.

Axline, V. M. (1974). Dibs em busca de si mesmo. Rio de Janeiro: Agir.

Axline, V. M. (1984). Ludoterapia: A dinâmica interior da infância. Belo Horizonte: Interlivros. (Original publicado em 1947)

Benjamin, W. (1994). O narrador: Considerações sobre a obra de Nikolai Leskov. In W. Benjamin (Org.), Magia e técnica, arte e política: Ensaios sobre literatura e história da cultura. São Paulo: Brasiliense. (Original publicado em 1936)

Buys, R. (2001). A não-diretividade. Rio de Janeiro: Mimeo.

Freire, E. (2000). A implementação das atitudes facilitadoras na relação terapêutica centrada no cliente. Dissertação de mestrado não-publicada, Centro de Ciências da Vida, Pontifícia Universidade Católica de Campinas, Campinas, SP.

Messias, T. S. C. (2002). Plantão psicológico como possibilidade de facilitação de tendência atualizante: Um estudo clínico. Dissertação de mestrado não-publicada, Centro de Ciências da Vida, Pontifícia Universidade Católica de Campinas, Campinas, SP.

Morato, H. T. P. (1999). Entrevista à Revista Redepsi, no lançamento do livro aconselhamento psicológico centrado na pessoa. São Paulo: Casa do Psicólogo.

Rogers, C. R. (1980). Um jeito de ser. São Paulo: EPU.

Rogers, C. R., \& Kinget, M. S. (1977). Psicoterapia e relações humanas: Teoria e prática da terapia não diretiva (M. H. Bizzoto, Trad.). Belo Horizonte: Interlivros.

Szymansky, H. (2006). Práticas educativas familiares e o sentido da constituição identitária. Paidéia (Ribeirão Preto), 16, 81-90.

Tassinari, M. (2003). A clínica da urgência psicológica: Contribuições da abordagem centrada na pessoa e da teoria do caos. Tese de Doutorado não-publicada, Instituto de Psicologia, Universidade Federal do Rio de Janeiro, Rio de Janeiro, RJ.
Ana Paula de Sá Campos é Mestre pelo Programa de Pósgraduação em Psicologia da Pontifícia Universidade Católica de Campinas.

Vera Engler Cury é Professora Titular da Faculdade de Psicologia e do Programa de Pós-graduação em Psicologia do Centro de Ciências da Vida da Pontifícia Universidade Católica de Campinas.
Recebido: 05/03/2008

$1^{a}$ revisão: $14 / 10 / 2008$

$2^{a}$ revisão: $26 / 01 / 2009$

Aceite final: 05/02/2009 